\title{
A IMPORTÁNCIA DOS FESTIVAIS NA FORMAÇÃO DO ARTISTA
}

\section{Márcia Maria Strazzacappa Hernández}

\section{Resumo}

O presente texto relata as experiências de formação artística da autora, destacando o papel dos Festivais como instrumento desta formação. $\mathrm{O}$ texto discute ainda o preconceito enfrentado pelos professores de arte e artistas em geral.

\section{Palavras-Chave}

Arte ; Formação artística ; Professor de arte ; Artista

\begin{abstract}
The present text shows the artistic formation experiences of the author. It emphasizes the hole of Festival as instrument of this formation. This paper also discuss the prejudice that art teachers and artists should face.
\end{abstract}

Key words

Art ; Artistic formation ; Art teacher ; Artist.

\footnotetext{
${ }^{1}$ Este trabalho foi apresentado na mesa redonda "O ensino de Arte" no I Festival do Instituto de Artes, promovido pelo CAIA - Centro Acadêmico do Instituto de Artes em parceria com o Instituto de Artes, dia 11 de outubro de 2000 no Centro de Convenções da UNICAMP. Participaram da mesa Profa. Dra. Ana Angélica Albano - Faculdade de Educação/UNICAMP (coord.), Profa. Glória Cunha - Instituto de Artes/UNICAMP, Tiche Vianna - Barracão Teatro.
} 
Vou iniciar minha fala seguindo o discurso de Glória quando menciona as críticas constantes tecidas aos artistas por não serem sérios, e aos professores de artes, por - além de não serem sérios serem artistas frustrados.

No meu trajeto para a universidade, passo próximo a Moradia Estudantil e costumo dar carona para estudantes. No carro, a conversa é sempre a mesma: que curso você faz? Certo dia, três rapazes entraram no carro e ouvi a pergunta de sempre. Embora não sendo mais aluna, não quis entrar no mérito da questão, e respondi: dança. No ato, os três exclamaram: Nossa, que legal!! Retruquei: e vocês? E eles seriamente: Física. Perguntei ainda: vocês gostam? Gostamos - foi a resposta. Exclamei então por minha vez: Nossa!! Deve ser super legal fazer Física. Silêncio.

Este episódio ilustra um dos tabus que nós artistas enfrentamos por termos optado pela Arte como profissão. A Arte não é séria. Ela é supérflua, luxo, verniz. Isto nos reporta a crítica de Ciro Giordano BRUNI, no colóquio L'Enseignement de la danse et après! ( $\mathrm{O}$ ensino da dança e depois!) quando afirmava que "da mesma forma que falta um pouco de divertimento nas aulas de ciências, falta um pouco de seriedade nas aulas de arte. 2 Ele criticava a postura dos próprios professores de arte que ao invés de serem os primeiros a lutar pelo reconhecimento da arte na escola, acabam por reforçar em suas atitudes este discurso de que as aulas de arte são apenas para a recreação.
Em Paris tive o privilégio de estudar numa universidade cuja pró-reitora além de ser mulher era da área das artes. Por mais que na Europa, de uma maneira geral, as artes sejam mais valorizadas, os cargos administrativos superiores de universidades tradicionais são geralmente ocupados pelos grandes homens da filosofia ou da antropologia. Este fato era no mínimo um feito. Na cerimônia de recepção aos alunos do doutorado em artes, foi muito belo o discurso de abertura. Citaram a fala de um astrofísico francês que dizia que a Ciência precisava da Arte da mesma forma que a Arte da Ciência. Uma nova estrela não pode ser descoberta se ninguém imaginou ou sonhou sua existência antes. Poderíamos nos reportar a BRECHT igualmente quando ele dizia: "aqueles que não entendem nada da arte nem da ciência acreditam que são duas coisas imensamente diferentes, logo ignoram tudo. Eles imaginam ajudar a ciência lhe permitindo ser sem imaginação e fazer progredir a arte, impedindo a qualquer um de atingir a inteligência. (...) Não existe ninguém que seja totalmente desprovido de saber, da mesma forma que não existe ninguém que seja totalmente desprovido de arte,

Da mesma forma como tendemos a contrapor Arte e Ciência, compartimentalizamos a própria arte dividindo-a em caixinhas. Observem, por exemplo, a composição desta mesa. Há um representante de cada área: Tiche Vianna, do teatro; Glória Cunha, da música; Ana Albano da Artes Plásticas e eu da dança. Cada qual aqui classificado segundo sua especialidade, embora haja

\footnotetext{
${ }^{3}$ BRECHT, Bertold - L'Achat du cuivre, Seuil, Paris, 1989 (trad. do autor).

${ }^{2}$ BRUNI, Ciro Giordano - L'enseignement de la danse et après! - rencontres dans les universités Paris V et VIII, Paris, setembro 1998. (trad. do
} autor). 
muito de movimento, cor, textura, ritmo e poesia em todas nós.

Enquanto cursava minha graduação, durante muito tempo, sofri com esta compartimentalização. $\mathrm{O}$ problema não estava na classificação em si, mas no discurso subliminar que a sustentava. $\mathrm{Na}$ faculdade de educação era vista como "artista" (onde se podia ler: pedagoga menor). Quando na faculdade de dança, cursando concomitantemente a pósgraduação na educação, era tida como "intelectual"(onde se lia: bailarina menor) - No núcleo teatral onde trabalhava, era considerada "bailarina" (onde se lia atriz menor). Quanto aos espetáculos que apresentava, o público enlouquecia na tentativa de classifica-los. Afinal, aquilo era dança, mímica ou teatro experimental?

Como disse Ana Angélica na apresentação dos componentes da mesa, fui aluna da primeira turma da faculdade de dança da UNICAMP, o primeiro curso superior de dança de uma universidade pública no Estado de São Paulo. Fui igualmente aluna da pedagogia (não da primeira turma) e meu Mestrado também foi realizado na Faculdade de Educação. Ser aluna de primeira turma é uma experiência e tanto. Além de viver todo o entusiasmo do corpo docente de um curso em implantação, de um curso inédito, vive-se igualmente todos os conflitos e frustrações. Dos 25 alunos, apenas 11 se formaram. É interessante perceber que, de certa forma, nós alunos das primeiras turmas fomos responsáveis pelo curso que vocês têm hoje. Da mesma forma como na décima edição do Festival, (torcendo para que chegue até lá), vocês também terão sido responsáveis. É o aprendizado de duplo sentido. É a contribuição que os alunos têm a dar à universidade, à educação.
Há muitos anos não havia na UNICAMP um Festival de Teatro. Na verdade, a vida dos Festivais Internacionais de Teatro, patrocinados pela universidade em parceria com a Prefeitura Municipal de Campinas, foi muito curta. De uma primeira Mostra realizada em julho de 1989 que funcionou como uma extensão de um grande festival acontecido no Sul, os FIT tiveram apenas três edições nos anos consecutivos. Talvez muitos de vocês aqui presentes hoje, dada a juventude, desconheçam completamente este fato. Sim, a universidade sediou Festivais que contaram com a presença de grandes nomes do mundo artístico internacional. A última edição aconteceu em 1992. Desde então, ficou um vazio.

Foi com muita alegria que tomei conhecimento desta iniciativa dos alunos de realizarem um festival não apenas de teatro, mas um Primeiro Festival do Instituto de Artes. São vários os motivos para tamanha satisfação. Primeiro por ouvir novamente a palavra FESTIVAL no campus universitário; segundo, por ter sido iniciativa dos alunos e perceber a mobilização do Instituto de Artes como um todo, onde alunos, professores e funcionários da pós-graduação e das diferentes graduações (dança, teatro, música e artes plásticas) se envolveram; terceiro pelo caráter educativo dos mesmos.

Não quero aqui iniciar um discurso pedagógico antiquado. Mas não posso deixar de lado o tema central desta mesa que é falar do ensino das artes. Embora minha presença aqui seja para falar da dança, dou-me o direito de "sair um pouco de minha caixinha" para dividir com vocês minha experiência de formação enquanto artista e esta passou pela vivência em Festivais. 
Gostaria de enfatizar (talvez para aqueles que ainda tenham dificuldade de compreender a importância dos festivais na vida universitária dos alunos) o quanto se pode aprender participando deles. Os festivais têm uma vida curta, de fato, no entanto esta brevidade de tempo representa uma intensidade de força. São encontros, trocas, confrontos, integrações, brigas, dor de cabeça, etc. É a oportunidade de conhecer novos colegas, de outros cursos, de outras áreas (artes). É igualmente a oportunidade de re-conhecer o colega da turma numa outra situação que a sala de aula, dirigindo-lhe um outro olhar. É a oportunidade de compartilhar experiências artísticas ao lado de profissionais cujas vidas se passam longe do estabelecimento universitário.

Nas três versões do FIT que aconteceram na UNICAMP tive uma participação muito ativa em várias instâncias: na organização e na produção - meses antes do início; durante o festival, como tradutora-intérprete das oficinas, conferências e espetáculos; como artistaaluna, realizando alguns workshops e nas oficinas-montagens, como bailarinaintérprete.

As chamadas oficinas-montagens eram oficinas com um caráter diferenciado das demais. De duração mais longa, estas oficinas contavam com a participação de um grupo seleto de artistas, (diretor, cenógrafo, preparador corporal, músico compositor, etc.- dependendo do caráter da criação). O responsável pela oficina tinha a incumbência de ministrar um curso voltado para uma criação final que seria apresentada no último dia do Festival, para o encerramento. Muitas vezes, as oficinas-montagens começavam antes mesmo da abertura oficial do festival, para que os artistas tivessem mais tempo para selecionar os alunosintérpretes e trabalhar na montagem. O espetáculo podia ser uma criação inédita (como foram as montagens dirigidas por Ismael Ivo/ Marcio Aurelio e a de Toni Cots/Lucca Ruzza) ou remontagens de espetáculos já apresentados em outros países (como Antígona de Larry Tremblay e Sleep and reincarnation from the empty land de Natsu Nakajima). $\mathrm{O}$ que era interessante nestas oficinasmontagens era o contato com o mundo profissional internacional. Os alunos participantes das oficinas ficavam mergulhados durante dias num universo profissional de padrão internacional. A postura deles era completamente outra e isso eles traziam em seguida para a sala de aula. O ritmo era acelerado, afinal como montar um espetáculo inteiro de 60 minutos em 15, 20 ou 30 dias? Mas o empenho era significativo.

Alguns espetáculos apresentados foram alvo de críticas, não sem razão. No entanto, não podemos negar que mais do que $o$ produto final a vivência do processo foi o fator mais importante.

Minha dissertação de Mestrado em Educação partiu da observação das dificuldades corporais dos atores-alunos na realização dos ateliers e das oficinasmontagens dos festivais. As oficinas funcionaram como um verdadeiro laboratório, onde os alunos se desnudavam de seus hábitos e da situação "protegida" das aulas na universidade, onde todos (alunos e professores) conhecem suas qualidades e defeitos. Esta situação se apresentava como condição ideal para poder analisar o que realmente

\footnotetext{
${ }^{4}$ A referida dissertação intitula-se " $O$ corpo $\boldsymbol{e n -}$ cena”, (set.94) está disponível na Biblioteca da Faculdade de Educação da UNICAMP.
} 
ficara no corpo destes atores referente ao aprendizado técnico corporal que receberam no curso. Desta análise, um esboço de metodologia de trabalho corporal para atores viu o dia e mais tarde se transformou numa disciplina que foi implantada com sucesso no curso de graduação em Artes Cênicas. Como minha dissertação, outros estudos foram realizados a partir de investigações sobre os Festivais.

Grupos de teatro e dança também se formaram a partir de Festivais. Não esquecendo a história do desenvolvimento do ensino de arte no Brasil, onde os Festivais Universitários tiveram papel importante. (vide a obra recém-lançada do prof. Arão Paranaguá de Santana sobre as escolas de teatro no Brasil) ${ }^{\underline{6}}$.

Vários alunos, após esse contato com artistas estrangeiros, acabaram arrumando as malas e partindo para viver um tempo fora. Aí está outro ponto positivo dos festivais: os encontros que propiciam links, que abrem portas... Não que devamos ser a favor de exportar talentos, muito pelo contrário, mas cabe ressaltar a importância para o artista de conhecer outros horizontes, de desenvolver um outro olhar, de ver e conhecer o mundo.

Etienne Decroux, o pai da mímica abstrata francesa, afirmava de forma muito poética que: "Lembro-me de ter sido pintor, encanador, pedreiro, açougueiro, (...) reparador de vagão, lavador de prato, enfermeiro. (...) Estas coisas vistas e mesmo manipuladas passaram pouco a pouco por detrás de minha cabeça, desceram ao longo de meu

${ }^{5}$ SANTANA, Arão - Teatro e Formação de Professores, Editora EDUFMA, São Luís, 2000. braço, chegaram a ponta dos dedos onde modificaram minhas impressões digitais. » $\mathrm{E}$ acrescentava que "há gente que nunca viu nada disso. Eu me pergunto como eles podem pôr em cena um espetáculo". $\square$ Para ele, observar o mundo ao redor e sobretudo viver o mundo de forma intensa e dele pegar as bases de sua arte é a condição sine qua non para todo e qualquer artista.

Quando ministrava aulas para o primeiro ano da graduação em Artes Cênicas, costumava dar dois conselhos aos alunos ingressantes: 1- aprendam uma segunda língua e 2- façam suas malas. A justificativa para tais conselhos estava na certeza de que o artista para ser artista tem que ver o mundo. E não apenas com os olhos, mas com todos os sentidos. Neste exercício de ver o mundo é que aprendemos a desenvolver nosso olhar. E a arte é isso, é uma outra maneira de perceber as coisas ao nosso redor. Como Ana Angélica dizia em sua fala, a arte existe para podermos dizer algo. Logo, precisamos ver, descobrir e redescobrir o mundo para podermos ter coisas para dizer. Se os festivais têm este poder de nos permitir "ver coisas", os festivais sem dúvida contribuem para nossa formação de artistas.

Não tenho dúvidas dos problemas enfrentados por vocês para a organização do Festival. Mas esse foi o primeiro. Cabe ao final de tudo uma reflexão onde sejam anotados os sucessos e os fracassos. Os primeiros, para serem repetidos e os segundos, para serem lembrados, tentando-se evitar recair nos mesmos buracos. Da mesma forma como

\footnotetext{
6 DECROUX, Etienne - Paroles sur le mime, Librairie Théâtrale, Paris, 1994. (trad. do autor), p.8.

7 ibidem.
} 
a Arte, os Festivais, só se aprende, fazendo.

Gostaria de encerrar minha participação retomando a imagem do "vira-lata" que Tiche usou para retratar o que é ser brasileiro. Uma imagem que deveria nos honrar, pois o vira-lata é o símbolo do sucesso da mistura: o vira-lata não tem preocupação com um "passado nobre", não vive na expectativa de receber herança, tem uma resistência física invejável, vive (ou sobrevive) com o pouco que tem, e acima de tudo (ou talvez por causa disso), é extremamente criativo.

Essa imagem do brasileiro "vira-lata" me fez pensar em Jean-Marc Philippe, um artista plástico e astrofísico francês responsável por um dos projetos europeus para a comemoração do novo milênio. Seu projeto prevê o lançamento de uma nave espacial carregada de informações sobre o nosso planeta. Esta nave irá cumprir uma órbita de $50 \mathrm{mil}$ anos até retornar à Terra. A idéia é informar os habitantes do futuro sobre como era o planeta nos dias de hoje. As informações estão gravadas em CD-ROMs e junto aos CDs, Philippe criou uma escultura em vidro onde reproduziu em gravura centenas de rostos de diferentes culturas. Segundo o artista, esta placa de vidro é necessária para que os habitantes do futuro saibam como eram nossas fisionomias. Estas informações não caberiam em dados matemáticos e só através da arte elas poderiam atravessar o tempo. Só a arte pode se eternizar. (Vejamos o exemplo das pinturas rupestres de Lascaux). Quanto ao porquê da importância dada a preservação das imagens dos rostos, ele afirmou que: no futuro próximo, com o acelerado ritmo da miscigenação dos povos, nós teremos todos a mesma cara. No futuro, nós seremos todos brasileiros.
O "vira-lata” é o futuro de nossa espécie. 
Márcia Maria Strazzacappa Hernández Doutora em Estudos Teatrais e Coreográficos pela Universidade de Paris VIII

Professora do Departamento de Metodologia de Ensino da Faculdade de Educação / UNICAMP

Coordenadora do LABORARTE

e-mail - m.strazzacappa@uol.com.br 